\title{
Cold response of digital arteries in chain saw operators
}

\author{
N OLSEN, S L NIELSEN, AND P VOSS \\ From the Departments of Clinical Physiology, Hvidovre, and Herlev Hospitals, University of Copenhagen, \\ Copenhagen, and Department of Acoustics, Institute of Technology, Tåstrup, Denmark
}

\begin{abstract}
In a study of vibration-induced white finger (VWF) 39 chain saw operators, being representative of 365 lumberjacks according to a completed questionnaire, underwent clinical investigation. In a medical interview 13 of the 39 had VWF and 26 were without finger symptoms. In the subjects with VWF both hands were equally affected, the third and fourth finger most frequently; the thumbs were always normal. A cold provocation test, measuring the finger systolic blood pressure with a cuff technique during combined body cooling and finger cooling to 30,15 , and $6^{\circ} \mathrm{C}$, was applied to the 39 chain saw operators and to 20 age-matched outdoor workers who had not used vibrating hand tools. The finger most often showing Raynaud's phenomenon was cold provoked, and a non-affected finger was used as a reference. The systolic pressure gradient measured at $30^{\circ} \mathrm{C}$ from the upper arm to the cooled finger was increased in the chain sawyers most severely affected by VWF compared with the control group and with the chain sawyers without VWF $(p<0.02)$. Raynaud's phenomenon was verified by digital arterial closure (zero pressure in the finger) at 15 or $6^{\circ} \mathrm{C}$ in 12 of 13 chain sawyers having anamnestic and clinical evidence of VWF. Chain sawyers without VWF had an increased digital arterial response to cold at 15 and $6^{\circ} \mathrm{C}$ compared with the control group $(\mathrm{p}<0.05)$ and had a decreased cold response compared with chain sawyers with VWF $(\mathrm{p}<0.05)$. In chain sawyers without VWF 13 subjects with an exposure period of 10-23 years had an increased cold response at $6^{\circ} \mathrm{C}$ compared with 13 subjects with an exposure period of one to three years $(p<0.05)$. Only one of 38 chain saws did not exceed the exposure limit proposed by the International Standardisation Organisation. The results of the present study indicate that vibrations induce hyperresponsiveness to cold in the exposed arteries, even in chain sawyers without finger symptoms. The exposure to vibration therefore should be reduced to eliminate this damage. The presented cold provocation test may be used to diagnose Raynaud's phenomenon and to disclose an abnormal digital arterial cold response before subjective symptoms have appeared.
\end{abstract}

Vibration-induced white finger (VWF) is a secondary form of Raynaud's phenomenon caused by vibrating hand tools. Investigations of the frequency and severity of VWF are usually performed using medical interviews or questionnaires because of the lack of adequate diagnostic methods. ${ }^{1}$ Recently Nielsen and Lassen ${ }^{2}$ described a method for the routine investigation of Raynaud's phenomenon using finger systolic blood pressure measurements after cooling one finger to disclose vasospasm of the digital arteries. We used this method to investigate a group of chain saw operators and a control group.

Received 5 January 1981

Accepted 5 February 1981

\section{Materials and methods}

POPULATIONS STUDIED

In 1977-8 questionnaires were distributed to all workers in 18 forest districts, comprising about one-fifth of all forestry workers in Denmark. From the completed questionnaire it was found that a total group of 365 subjects worked with chain saws, excluding 11 subjects with primary finger symptoms (the investigation will be reported in detail elsewhere). The present study included all 66 workers in two of these districts. All 66 employees answered the questionnaire but 12 did not answer the questions concerning vibration exposure finger symptoms, six had never used a chain saw, three had stopped 
working with chain saws more than one year earlier, and one had Raynaud's phenomenon before vibration exposure started. These 22 subjects were thus excluded from further study.

In a field study comprising a medical interview, a cold provocation test, and vibration measurements three of the remaining 44 subjects were absent, one was missed for technical reasons, and one was excluded because of traumatic lesions to all the fingers. The group investigated, therefore, finally included 39 subjects. The medical interview showed that they all used chain saws, were without primary finger symptoms, and none had metabolic or vascular disorders other than VWF. Included in the group were two subjects who had used pneumatic hand tools without having VWF and three who had been treated at hospitals for traumatic lesions of the hands but who had no sequelae. The age distribution, exposure period, number of subjects with VWF, and latency period of VWF (defined as the difference in time between the exposure period and the duration of VWF) are given in table 1 for the total group of 365 subjects and the test sample of 39 subjects as evaluated from the completed questionnaire. These variables did not differ significantly between the 39 subjects and the

Table 1 Characteristics of chain saw operators in total group and subsample according to answers to a questionnaire. Values are given as numbers or mean (SD)

\begin{tabular}{lcc}
\hline & Total group & Test-sample \\
\hline No of men & 365 & 39 \\
Age (yr) & $38 \cdot 9(15 \cdot 3)$ & $42 \cdot 6(17 \cdot 7)$ \\
Exposure period (yr) & $8 \cdot 5(7 \cdot 5)^{*}$ & $9 \cdot 7(7 \cdot 4)$ \\
No with VWF & 107 & 11 \\
Latency period (yr) & $5 \cdot 6(5 \cdot 5) \dagger$ & $5 \cdot 8 \quad(4 \cdot 2)$ \\
\hline
\end{tabular}

$*^{*} \mathrm{n}=352$.

†n $=90$. rest of the total group.

The stage assessments of VWF were based on the combined information from the completed questionnaire and the interview as described by Taylor and Pelmear ${ }^{3}$ and Chatterjee et al: ${ }^{4}$ stage 0 : no symptoms; stage $0_{\mathrm{N}} / 0_{\mathrm{T}}$ : intermittent numbness or tingling; stage 1 : blanching of one or more finger tips without any interference with work, domestic, or social activities; stage 2: blanching characterised by increased frequency and number of fingers affected, usually triggered by cold, and with slight interference with domestic and social activities, but not with work; stage 3 : extensive blanching with frequent episodes in summer and winter, with definite interference with work, domestic, and social activities; and stage 4: extensive blanching of all digits in summer and winter, leading to change of occupation. Of the 39 chain sawyers 26 were in stage 0 , none in stages $0_{\mathrm{N}} / 0_{\mathrm{T}}$ or 1 , six in stage 2 , and seven in stage 3 . The age distribution, smoking habits, use of gloves, exposure periods, and latency period of VWF are given in table 2 for the stages of VWF with stage 0 subdivided into two groups by the exposure period. The exposure period in years was higher in stage 3 than in stage $2(p=0.02)$.

As nearly all of the forestry workers had used vibrating hand tools a control group of 20 subjects working in a shipyard was investigated. The controls were selected according to the following criteria as confirmed from a medical interview: outdoorworking man, never worked with vibrating hand tools, without primary finger symptoms, and with no secondary causes of Raynaud's phenomenon. None of the 20 controls suffered from vascular or metabolic disorders. Included was one subject treated for an injury of the left hand but with no sequelae. The age distribution, number of smokers, and tobacco consumption did not differ significantly from that of the 39 chain sawyers (table 2).

Table 2 Age, smoking habits, use of gloves, exposure periods, and latency of $V W F$ in the study populations. Chain saw operators are grouped by stage of VWF with stage 0 subdivided into two groups by exposure period. Values are given as numbers or median (range)

\begin{tabular}{|c|c|c|c|c|c|c|c|}
\hline & \multirow{3}{*}{$\begin{array}{l}\text { Control } \\
\text { group }\end{array}$} & \multicolumn{4}{|c|}{ Chain saw operators } & \multirow{2}{*}{\multicolumn{2}{|c|}{$\frac{\text { Stage } 0 \text { subdivided }}{\text { Exposure period }(y r)}$}} \\
\hline & & \multirow[t]{2}{*}{ Stage 0} & \multirow[t]{2}{*}{ Stage 2} & \multirow[t]{2}{*}{ Stage 3} & \multirow[t]{2}{*}{ Total } & & \\
\hline & & & & & & $1-3$ & $10-23$ \\
\hline No of men & 20 & 26 & 6 & 7 & 39 & 13 & 13 \\
\hline Age (yr) & $37(26-57)$ & $30(18-65)$ & $46(18-62)$ & $62(49-67)^{*} \dagger$ & $46(18-67)$ & $21(18-28)+$ & $57(32-65)$ \\
\hline Smokers (No) & 10 & 13 & 4 & 5 & 22 & 8 & 5 \\
\hline Tobacco/day (g) & $13(10-20)$ & $15 \quad(3-63)$ & $17 \quad(8-63)$ & $27(10-80)^{*}$ & $16 \quad(3-80)$ & $10(3-28)$ & $17 \quad(4-63)$ \\
\hline Use of gloves (No) & & & 4 & 3 & 28 & & 9 \\
\hline Exposure period (yr) & & $7(1-23)$ & $6(2-15)$ & $16(6-20) \dagger$ & $10(1-23)$ & $1(1-3)$ & $16(10-23)$ \\
\hline Exposure period (h/day) & & $3-5(0-8)$ & $3-5(0-8)$ & $3-5(1-8)$ & $3-5(0-8)$ & $3-5(3-8)$ & $3-5(0-8)$ \\
\hline Latency period $(\mathrm{yr})$ & & & $5(2-10) n=4$ & $5(0-15)$ & $5(0-15) n=11$ & & \\
\hline
\end{tabular}

*Significant from control group ( $p<0.05)$.

†Significant from stage $0(p<0.05)$.

†Significance between subgroups in stage 0 (p $<0.05$ ). 


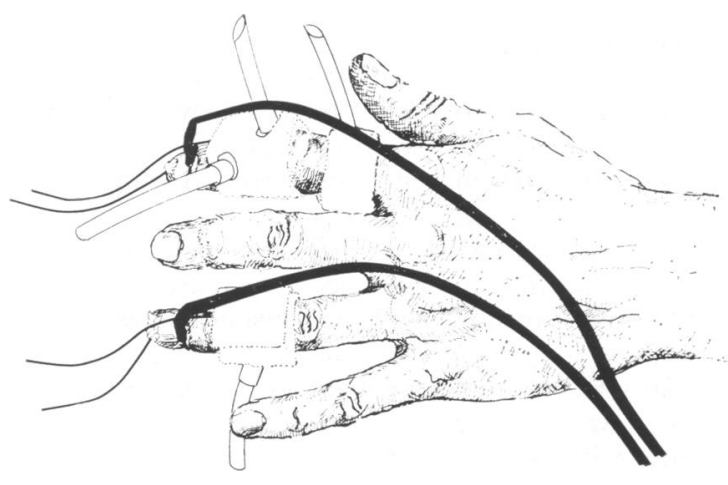

Blood pressure cuffs on midphalanx of second and fourth fingers with a strain-gauge on outer phalanx and thermocouples beneath pressure cuffs. Double-inlet cuff on second finger can be pressurised or perfused with water at preset temperatures. Cuff on proximal phalanx of this finger is used as a tourniquet during cooling of midphalanx.

\section{METHODS}

All 59 men answered a questionnaire concerning their working conditions (type of vibrating hand tool and duration of use), finger symptoms (questions referred earlier ${ }^{5}$ ), smoking habits, treatment for hand injury, and treatment for other diseases (diabetes, arterial hypertension, ischaemic heart and leg disease). In a medical interview the answers to the questionnaire were controlled and improved if necessary, and the subjects were asked about the distribution of the fingers affected by Raynaud's phenomenon, defined as cold-provoked episodes of well-demarcated pallor affecting one or more fingers. ${ }^{6}$

The subjects were investigated in the supine position after $10 \mathrm{~min}$ of rest with their fingers at heart level and dressed in indoor clothing. Body cooling was performed by a cooling blanket perfused continuously with water at $8-12^{\circ} \mathrm{C} 10 \mathrm{~min}$ before the measurements. Only fingers without any history of traumatic lesions were investigated. In subjects with
VWF the finger most frequently showing Raynaud's phenomenon according to the medical interview was cold provoked and a non-affected finger was used for a reference. In subjects without VWF the same fingers were used as in subjects with VWF, usually the middle finger with the thumb as a reference. Finger cooling was performed using a double-inlet cuff on the midphalanx during $5 \mathrm{~min}$ ischaemia produced with an occluding cuff on the proximal phalanx ${ }^{2}$ (fig). Finger systolic blood pressure (FSP) was measured by strain-gauge technique ${ }^{7}$ after cooling to 30,15 , and $6^{\circ} \mathrm{C}$ (for further details see Olsen and Nielsen ${ }^{8}$ ). FSP at each of the two lower temperatures $(x)$ in the thermostated finger (th) was expressed as percentage of the pressure at $30^{\circ} \mathrm{C}$ in the same finger corrected for changes in arterial blood pressure during the investigation:

FSP $\%(x)=\frac{100 \times \text { FSP }_{\text {th, } x}}{\left.\text { FSP }_{\text {th, } 30-\left(\text { FSP }_{\text {reP, }} \mathbf{s} 30-\text { FSP }_{\text {ref, }} \mathbf{s x}\right.}\right)}$

where FSP $_{\text {ref, }} \mathrm{sx}$ is the pressure measured simultaneously on a non-cooled reference finger of the same hand. ${ }^{9}$ The reduction in FSP by finger cooling from $30^{\circ} \mathrm{C}$ to 15 or $6^{\circ} \mathrm{C}$ (R-FSP) was also calculated: R-FSP (x) $=$ FSP $_{\text {th, } 30}-$ FSP $_{\text {th, } x}-\left(\right.$ FSP $_{\text {ref, }}$ s30 FSP ref, sx). Raynaud's phenomenon with digital arterial closure as defined by Lewis ${ }^{10}$ was verified by the presence of a zero pressure in the finger at 15 or $6^{\circ} \mathrm{C}$. Subjects with a zero pressure at $15^{\circ} \mathrm{C}$ were not tested at $6^{\circ} \mathrm{C}$. Arm blood pressure was measured by auscultation with a 12-cm broad cuff on the upper arm of the same side as FSP was measured. The outdoor and room temperatures during the investigations were higher in the control group $\left(10-17^{\circ} \mathrm{C}\right.$ and $\left.16-19^{\circ} \mathrm{C}\right)$ than in the vibration-exposed group $\left(-10\right.$ to $5^{\circ} \mathrm{C}$ and $\left.9-16^{\circ} \mathrm{C}\right)$. There was no significant difference between the two groups with respect to the temperature of the reference finger $\left(20-35^{\circ} \mathrm{C}\right)$ or between the reference finger and thermostated finger at $30^{\circ} \mathrm{C}$. The precision of the cold provocation test was estimated for randomly selected chain sawyers from double determinations

Table 3 Precision of the cold provocation test estimated from measurements repeated with an interval of 10 min in chain saw operators. Finger systolic pressure in reference finger $\left(F S P_{r e f}\right)$ and in finger thermostated at $30^{\circ} \mathrm{C}$ $\left(F S P_{t h},{ }_{30}\right)$, reduction in pressure by cooling to 15 or $6^{\circ} \mathrm{C}(R-F S P)$, and pressure at 15 and $6^{\circ} \mathrm{C}$ expressed in percentage of pressure at $30^{\circ} \mathrm{C}(\mathrm{FSP} \%)$. The $95 \%$ confidence limits of a single determination was calculated as $t \sqrt{\Sigma d^{2} / 2 n}$, where $t$ is "Students $t, " d$ is difference between two repeated measurements, and $n$ is number of duplicates

\begin{tabular}{|c|c|c|c|c|c|c|}
\hline & $\begin{array}{l}\text { FSPref } \\
(n=32) \\
(m m H g)\end{array}$ & $\begin{array}{l}F S P_{t h,}, 30 \\
(n=32) \\
(m m H g)\end{array}$ & $\begin{array}{l}R-F S P\left(15^{\circ} C\right) \\
(n=19) \\
(m m H g)\end{array}$ & $\begin{array}{l}R-F S P\left(6^{\circ} C\right) \\
(n=13) \\
(m m H g)\end{array}$ & $\begin{array}{l}F S P \%\left(15^{\circ} C\right) \\
(n=19) \\
(\%)\end{array}$ & $\begin{array}{l}F S P \%\left(6^{\circ} C\right) \\
(n=13) \\
(\%)\end{array}$ \\
\hline $\begin{array}{l}\text { Mean of first determination } \\
\text { Range of first determination } \\
\text { Mean difference } \\
\sqrt{\overline{\sum d^{2} / 2 n}} \\
95 \% \text { confidence limits }\end{array}$ & $\begin{array}{l}123 \\
95-180 \\
-1 \cdot 1 \\
2 \cdot 9 \\
5 \cdot 8\end{array}$ & $\begin{array}{l}115 \\
80-155 \\
-0.9 \\
2 \cdot 8 \\
5 \cdot 7\end{array}$ & $\begin{array}{l}34 \\
0-145 \\
0 \cdot 8 \\
8 \cdot 0 \\
16 \cdot 7\end{array}$ & $\begin{array}{l}52 \\
20-100 \\
8 \cdot 1^{*} \\
8 \cdot 8 \\
19 \cdot 1\end{array}$ & $\begin{array}{l}71 \\
0-100 \\
-1 \cdot 2 \\
6 \cdot 2 \\
13 \cdot 0\end{array}$ & $\begin{array}{c}59 \\
36-79 \\
-5 \cdot 8^{*} \\
6 \cdot 0 \\
13 \cdot 0\end{array}$ \\
\hline
\end{tabular}

*Significant from zero $(p<0.05)$. 
Table 4 Distribution of fingers affected by VWF in chain saw operators. Values are given as numbers or median (range)

\begin{tabular}{lccc}
\hline Finger & $\begin{array}{l}\text { Right hand } \\
(n=12)\end{array}$ & $\begin{array}{c}\text { Left hand } \\
(n=12)\end{array}$ & $\begin{array}{c}\text { Both hands } \\
(n=12)\end{array}$ \\
\hline Thumb & 0 & 0 & 0 \\
Index & 5 & 4 & $9^{*}$ \\
Middle & 9 & 10 & $19^{*}$ \\
Ring & 9 & 10 & 19 \\
Little & 4 & 5 & $9^{*}$ \\
Total & 27 & 29 & 56 \\
Median (range) & $2(0-4)$ & $2(0-4)$ & $4(2-8)$ \\
\hline
\end{tabular}

*Significant from digit immediately above $(\mathrm{p}<0.05)$.

One subject in stage 2 could not inform the distribution.

with an interval of $10 \mathrm{~min}$ (table 3 ).

The vibration measurements as root mean square value $\left(\mathrm{m} / \mathrm{s}^{2} \mathrm{rms}\right)$ were made with a Bruel and Kjaer triaxial accelerometer mounted rigidly to the chain saw. The signals from the accelerometer were amplified, recorded on tape, and analysed into 1/3-octave bands between $6 \cdot 3$ and $1000 \mathrm{~Hz}$. The principles of the measurement and the evaluation of the results were in accordance with the "Draft International Standard" proposed by the International Standardisation Organisation. ${ }^{11}$ As the daily median exposure period was three to five hours (table 2) the vibration exposure limit of four hours' continuous chain sawing was used as the reference. Measurements were performed on 38 of 39 chain saws used by the workers and during normal use.

Statistical evaluation was performed by nonparametric statistics with a significance limit of 0.05 (two-sided). The difference in numerical measurements between two related samples and between two independent samples was tested with the Wilcoxon matched-pairs signed rank test and the MannWhitney rank sum test. Normal $95 \%$ confidence limits were calculated from the $t$-distribution.

\section{Results}

FINGERS AFFECTED BY VWF

The fingers affected by VWF are given in table 4 . In eight subjects the symptoms occurred symmetrically. Five subjects with a median exposure period of six years (range 3-12) had a median of three affected fingers (range 2-4), which was lower than six affected fingers (2-8) in seven subjects with an exposure period of 16 years $(15-20)(p=0.05)$.

SYSTOLIC BLOOD PRESSURE AT $30^{\circ} \mathrm{C}$

The systolic blood pressures at $30^{\circ} \mathrm{C}$ in the investigated groups are compared in table 5 . The systolic pressure gradient measured at $30^{\circ} \mathrm{C}$ from the upper arm to the cooled finger was increased in stage 3 compared with stage 0 and with the control group $(p<0.02)$. This pressure gradient was also increased in stage 3 compared with the subgroup of stage 0 with the longest exposure period $(p<0.02)$, that had an exposure period not different from stage $3(p>$ $0 \cdot 10)$.

\section{DIGITAL ARTERIAL COLD RESPONSE}

The digital arterial cold responses in the investigated groups are compared in table 6 . In the control group the lower $95 \%$ confidence limits of FSP $\%$ were estimated as $68 \%$ at $15^{\circ} \mathrm{C}$ and $58 \%$ at $6^{\circ} \mathrm{C}$, and the upper $95 \%$ confidence limits of R-FSP were estimatd as $35 \mathrm{~mm} \mathrm{Hg}$ at $15^{\circ} \mathrm{C}$ and $44 \mathrm{~mm} \mathrm{Hg}$ at $6^{\circ} \mathrm{C}$. FSP $\%$ was decreased and R-FSP increased by cooling the

Table 5 Systolic blood pressure on the upper arm $(A S P)$, reference finger $\left(F S P_{\text {ref }}\right)$, and finger thermostated at $30^{\circ} C$ $\left(F S P_{t h},{ }_{30}\right)$. Chain saw operators are grouped by stage of VWF with stage 0 subdivided into two groups by the exposure period. Values are given as median and range

\begin{tabular}{|c|c|c|c|c|c|c|}
\hline \multirow{3}{*}{$\begin{array}{l}\text { Pressure } \\
(\mathrm{mm} \mathrm{Hg})\end{array}$} & \multirow{3}{*}{$\begin{array}{l}\text { Control } \\
\text { group } \\
(n=20)\end{array}$} & \multicolumn{3}{|l|}{ Chain saw operators } & \multirow{2}{*}{\multicolumn{2}{|c|}{$\frac{\text { Stage } 0 \text { subdivided }}{\text { Exposure period }(y r)}$}} \\
\hline & & \multirow{2}{*}{$\begin{array}{l}\text { Stage } 0 \\
(n=26)\end{array}$} & \multirow{2}{*}{$\begin{array}{l}\text { Stage } 2 \\
(n=6)\end{array}$} & \multirow{2}{*}{$\begin{array}{l}\text { Stage } 3 \\
(n=7)\end{array}$} & & \\
\hline & & & & & $\begin{array}{l}I-3 \\
(n=13)\end{array}$ & $\begin{array}{l}10-23 \\
(n=13)\end{array}$ \\
\hline ASP & 130 & 138 & 125 & 143 & 130 & $140 \div$ \\
\hline \multirow[t]{2}{*}{ FSPref } & $\begin{array}{l}110-160 \\
115\end{array}$ & $\begin{array}{l}110-180(n=22) \\
128\end{array}$ & $\begin{array}{l}120-140 \\
105\end{array}$ & $\begin{array}{l}130-175(n=6) \\
120\end{array}$ & $\begin{array}{l}110-140(n=10) \\
115\end{array}$ & $\begin{array}{l}120-180(n=12) \\
130\end{array}$ \\
\hline & $80-155$ & $100-180$ & $100-120$ & $80-160$ & $100-160$ & $100-180$ \\
\hline \multirow[t]{2}{*}{$\mathrm{FSP}_{\mathrm{th}}, \mathbf{3 0}$} & 110 & 120 & 98 & 110 & 105 & 130 \\
\hline & $80-135$ & $85-150$ & $80-125$ & $80-135$ & $85-140$ & $85-150$ \\
\hline \multirow{2}{*}{ FSPret - FSP $_{\text {th, }}$ so } & 0 & 5 & 13 & 5 & 10 & 5 \\
\hline & -20 to 30 & -25 to 35 & -15 to 35 & $0-25$ & -15 to 35 & -25 to 35 \\
\hline ASP - FSPref & $\begin{array}{l}13 \\
-10 \operatorname{to} 35\end{array}$ & 10 & 20 & 18 & $\begin{aligned} & 10 \\
- & 20 \text { to } 25(n=10)\end{aligned}$ & ${ }_{0-25}^{13}(n=12)$ \\
\hline \multirow[t]{2}{*}{$A S P-F S P_{t h}, 30$} & $\begin{array}{l}-10 \text { to } 35 \\
20\end{array}$ & -20 to $25(n=22)$ & 30 & $\begin{array}{l}10-50(n=6) \\
38 * \dagger\end{array}$ & 18 & 18 \\
\hline & $0-40$ & -15 to $55(n=22)$ & $10-50$ & $20-50(n=6)$ & -15 to $55(n=10)$ & -10 to $35(n=12)$ \\
\hline
\end{tabular}

* Significant from control group ( $p<0.05)$.

†Significant from stage $0(\mathrm{p}<0.05)$.

${ }_{+}$Significance between subgroups in stage $0(p<0.05)$. 
Table 6 Cold provocation test. Reduction in finger systolic blood pressure by finger cooling to 15 and $6^{\circ} \mathrm{C}$ from $30^{\circ} \mathrm{C}$ $(R-F S P)$, and pressure at 15 and $6^{\circ} \mathrm{C}$ in percentage of pressure at $30^{\circ} \mathrm{C}(\mathrm{FSP} \%)$. Chain saw operators are grouped by stage of $V W F$ with stage 0 subdivided into two groups by exposure period. Subjects with a zero pressure at $15^{\circ} \mathrm{C}$ were not tested at $6^{\circ} \mathrm{C}$. Values are given as median and range

\begin{tabular}{|c|c|c|c|c|c|c|}
\hline & \multirow{3}{*}{$\begin{array}{l}\text { Control } \\
\text { group } \\
(n=20)\end{array}$} & \multicolumn{3}{|l|}{ Chain saw operators } & \multicolumn{2}{|c|}{ Stage 0 subdivided } \\
\hline & & \multirow{2}{*}{$\begin{array}{l}\text { Stage } 0 \\
(n=26)\end{array}$} & \multirow{2}{*}{$\begin{array}{l}\text { Stage } 2 \\
(n=6)\end{array}$} & \multirow{2}{*}{$\begin{array}{l}\text { Stage } 3 \\
(n=7)\end{array}$} & \multicolumn{2}{|c|}{ Exposure period $(y r)$} \\
\hline & & & & & $\begin{array}{l}l-3 \\
(n=13)\end{array}$ & $\begin{array}{l}10-23 \\
(n=13)\end{array}$ \\
\hline $\begin{array}{c}\text { R-FSP }\left(15^{\circ} \mathrm{C}\right) \\
(\mathrm{mm} \mathrm{Hg})\end{array}$ & $\begin{array}{l}10^{*} \\
-5 \text { to } 30\end{array}$ & $\begin{array}{l}20 \dagger \\
0-150\end{array}$ & $\begin{array}{l}63 * \dagger \\
20-125\end{array}$ & $\begin{array}{l}105 * \dagger \\
75-135\end{array}$ & $\begin{array}{l}20 \\
0-90\end{array}$ & $\begin{array}{l}30 \\
0-150\end{array}$ \\
\hline $\begin{array}{l}\text { R-FSP }\left(6^{\circ} \mathrm{C}\right) \\
(\mathrm{mm} \mathrm{Hg})\end{array}$ & $20^{*}$ & $\begin{aligned} & 40 \dagger \\
- & 10 \text { to } 125(n=24)\end{aligned}$ & $\begin{array}{l}75 \\
60-120(n=3)\end{array}$ & & $\begin{array}{l}30 \ddagger \\
-10 \text { to } 125\end{array}$ & $\begin{array}{l}80 \\
25 \text { to } 125(n=11)\end{array}$ \\
\hline $\mathrm{FSP} \%\left(15^{\circ} \mathrm{C}\right)$ & $\begin{array}{l}91^{*} \\
70-105\end{array}$ & $\begin{array}{l}79 \dagger \\
0-100\end{array}$ & $\begin{array}{l}30^{*+} \\
0-82\end{array}$ & $\begin{array}{l}0 * \dagger \\
0-0\end{array}$ & $\begin{array}{l}84 \\
28-100\end{array}$ & 76 \\
\hline FSP $\%\left(6^{\circ} \mathrm{C}\right)$ & $\begin{array}{l}83^{*} \\
60-100\end{array}$ & $\begin{array}{l}64 \dagger \\
0-107(n=24)\end{array}$ & $\begin{array}{l}0 \\
0-43(n=3)\end{array}$ & & $\begin{array}{c}76 \pm \\
0-107\end{array}$ & ${ }_{0-78}^{41}(n=11)$ \\
\hline
\end{tabular}

*Significant from stage $0(p<0.05)$.

†Significant from control group $(p<0.05)$.

†Significance between subgroups in stage 0 (p < 0.05$)$.

finger from 30 to $15^{\circ} \mathrm{C}$ and from 15 to $6^{\circ} \mathrm{C}(\mathrm{p}<0.05)$. Between the 10 youngest and the 10 eldest subjects in the control group the cold responses did not differ significantly. All 13 chain sawyers with VWF had an abnormal FSP $\%$ and R-FSP compared with the $95 \%$ confidence limits (table 6). The differences in FSP\% and R-FSP were not significant between stages 2 and $3(p>0 \cdot 10)$. Compared with the $95 \%$ confidence limits FSP $\%$ was abnormal in five subjects and R-FSP abnormal in three subjects in the subgroup of stage 0 with shortest exposure period, and FSP $\%$ and R-FSP were abnormal at 15 or $6^{\circ} \mathrm{C}$, or both, in 10 subjects in the subgroup with the longest exposure period. The difference in the number of subjects with an abnormal R-FSP was significant between the two subgroups in stage $0(p=0.02)$.

Twelve of 13 chain sawyers with VWF and five of 26 chain sawyers without VWF had a zero pressure in the finger at 15 or $6^{\circ} \mathrm{C}$. In the diagnosis of Raynaud's phenomenon the cold provocation test therefore had a nosographic sensitivity of $0.92(0.64-1.00)$, a nosographic specificity of $0.81(0.61-0.93)$, a predictive value of a positive test (zero pressure) of 0.71 $(0.44-0.90)$, and a predictive value of a negative test (pressure above zero) of $0.95 \quad(0.77-1.00)(95 \%$ confidence limits in parentheses). The prevalence of VWF was $0.33(0 \cdot 19-0 \cdot 50)$. None of the controls has a zero blood pressure by finger cooling.

VIBRATION CHARACTERISTICS

Expressed as median (first and third quartile in parentheses) the maximal 1/3-octave band excess of the saws compared with the ISO draft standard was 11 decibel (9-13) (reference $10^{-6} \mathrm{~m} / \mathrm{s}^{2}$ ) centred on the $125 \mathrm{~Hz}$ octave band (rotation frequence of the motor when the chain saws were used normally). Only one of 38 chain saws did not exceed the proposed exposure limit.

\section{Discussion}

FINGERS AFFECTED BY VWF

The number of fingers affected by VWF did not differ significantly between the two hands. In quarrymen using pneumatic hand tools, however, the fingers of the hand contralateral to the preferred working hand are the most affected. ${ }^{8}$ This difference in hand localisation of VWF between quarrymen and chain sawyers may be explained by the asymmetric position of the hands on the pneumatic tools with the non-preferred working hand nearest to the prepared stones and in that way most exposed to vibration, whereas both hands on the chain saw are nearly the same distance from the prepared material. In larger populations of chain sawyers with VWF than in the present study Hellstrøm and Andersen ${ }^{12}$ found $57 \%$ of the right-hand and $42 \%$ of the lefthand digits affected (123 subjects), and Pyykkö ${ }^{13}$ found more disease in the left hand. Pyykkô suggested that the left-hand grip force was higher than the right-hand grip force during work with chain saws and that this would be more exposed to vibration, but later Färkkilä et al $^{14}$ found grip forces to be equal in both hands during chain saw operations. In accordance with the present study other reports ${ }^{12-13}$ found the middle and ring fingers most often affected and the thumbs most often spared from symptoms. On average the subjects with longest exposure had most disease, suggesting a progression in the number of affected fingers with continuous 
exposure to vibrations.

SYSTOLIC BLOOD PRESSURES AT $30^{\circ} \mathrm{C}$ In the present study the systolic blood pressure gradient from the upper arm to the cooled finger at $30^{\circ} \mathrm{C}$ was increased in stage 3 compared with the control group and stage 0 , whereas the arm systolic blood pressure and the pressure gradient to the reference finger from the upper arm did not differ significantly between the three groups. This may reflect vibration-induced organic stenoses in the supplying arteries of the fingers most severely affected by VWF, or it may reflect arteriosclerosis because of a higher age distribution in stage 3 than in the other two groups. The pressure gradient from the upper arm to the cooled finger at $30^{\circ} \mathrm{C}$ was also higher in stage 3 than in the longest exposed subgroup of stage $0(p<0.02)$, which had an age distribution, smoking habits, and an arm systolic blood pressure not different from stage $3(p>0 \cdot 10)$, and this may support the hypothesis of vibrationinduced organic stenoses. No pressures in the fingers were below $80 \mathrm{~mm} \mathrm{Hg}$ at $30^{\circ} \mathrm{C}$, and as evaluated by visual inspection no fingers had ischaemic signs at this temperature. It had been found earlier ${ }^{8}$ that quarrymen had an increased pressure gradient from the upper arm to the fingers most often affected by VWF. Okada et al ${ }^{15}$ found the finger tip blood flow to be significantly lower in vibration-exposed groups compared with a control group even before cold provocation. Hirai ${ }^{16}$ observed that in patients with arterial occlusive disease only the fingers with arteriographic signs of occlusions in both digital arteries or in more proximal arteries leading to both sides of the finger had an increased systolic pressure gradient from the upper arm to the finger. This means that even a small increase in this gradient may indicate severe organic obstructions in the arteries. By arteriography James and Galloway ${ }^{17}$ found that subjects with severe VWF showed definite evidence of occlusions in the hand and digital arteries, and in nearly all fingers the presence of arterial occlusion coincided with the reporting of "white finger." In biopsy specimens of digital arteries from miners Ashe and Williams ${ }^{18}$ noticed pronounced subintimal fibrosis in men with mild to severe VWF and vascular lumen restriction without anatomical change in men with no or moderate finger symptoms.

\section{COLD PROVOCATION TEST}

In the diagnosis of Raynaud's phenomenon in chain sawyers the cold provocation test had the same sensitivity and specificity as had been found in a study of quarrymen. ${ }^{8}$ It was suggested ${ }^{8}$ that the sensitivity was as high as the best results obtained by other methods, and that subclinical Raynaud's phenomenon exists and can be disclosed by cold provocation at low temperatures. In the present study, however, the medical interview was regarded as the valid diagnostic method, and therefore zero pressures in subjects with possible subclinical VWF were classified as false-positive.

The precision of the cold provocation test at $15^{\circ} \mathrm{C}$ in chain sawyers was of about the same order as found in the study of quarrymen. ${ }^{8}$ At $6^{\circ} \mathrm{C}$ the mean difference of duplicates $(8 \mathrm{~mm} \mathrm{Hg})$ differed from zero with the most pronounced cold response at the first determination. As all but one subject with duplicate determinations at $6^{\circ} \mathrm{C}$ also were tested twice at $15^{\circ} \mathrm{C}$ the response of duplicates at $6^{\circ} \mathrm{C}$ may indicate a weakening of the vasoconstrictor response after too many rapidly repeated cold provocations. The relative high precision of the method compared with the variation in cold responses in chain sawyers without VWF suggests that it should be possible to distinguish between different gradings of cold response in these subjects.

The presented test discriminated between controls, stage 0 , and stages 2-3. Various objective tests had earlier been used to discriminate between controls, vibration-exposed subjects without VWF, and subjects with VWF. By observing the skin temperature of the finger in the rewarming period after cooling Pelmear et $\mathbf{~}^{19}$ found a large overlap between vibration-exposed subjects and controls, and skin temperature thermography did not distinguish vibration-exposed subjects from controls or the stages of VWF from each other. Okada et al ${ }^{15}$ measured the finger tip blood flow during and after cooling of the contralateral hand and found the flow to be lower in vibration-exposed subjects with and without VWF than in the controls, but the measurements could not discriminate between the two vibration-exposed groups. Chatterjee et $a l^{4}$ measured the somatic space-sense on non-cooled finger tips and found that 15 of 16 miners in stage 3 , four of five in stage 2, six of 21 in stage 0 , and four of 41 controls had an abnormal test result. We have evaluated their results statistically and found the number of abnormal test results to be higher in stages 3 and 2 than in the controls, and higher in stage 3 than in stage 0 , but no significant difference between the controls and stage 0 or between stages 0 and 2 . The difference in the discriminative capacity between the present method and the others may be due to differences in methodologies or in the populations studied.

The digital arterial cold response was expressed as FSP $\%$ and R-FSP. These expressions gave nearly the same results in the present study, probably because of the small differences in FSP th, 30 between the 
investigated groups. Which expression of cold response should be chosen is not clear but may depend on which problem is to be investigated.

\section{DIGITAL ARTERIAL COLD RESPONSE}

In the present study stages 3 and 2 had a significantly increased cold response compared with stage 0 , which had an increased response compared with the control group. This indicates that vibrations induce hyperresponsiveness to cold in the digital arteries, even in subjects without finger symptoms. There was no significant difference in the level of temperature provoking zero pressure between stages 2 and 3 . As all subjects in stage 3 and three of six subjects in stage 2 had a zero pressure at $15^{\circ} \mathrm{C}$ a higher test temperature than this might have given a better separation between the two stages. In stage 0 the subgroup with an exposure period of 10-23 years had a significantly increased cold response at $6^{\circ} \mathrm{C}$ compared with the subgroup with an exposure period of one to three years. The result indicates that vibrations induce increased cold responses as the exposure period increases in subjects without subjective finger symptoms, but this has to be finally confirmed in a prospective study.

All but one of the chain saws exceeded the proposed exposure limit, and even subjects who had used only modern vibration-damped chain saws showed VWF. In addition well-maintained saws were found to vibrate considerably less than poorly maintained saws. The results indicate that the vibration levels of the saws used or the exposure period, or both, should be reduced to eliminate the risk of VWF.

The cold provocation test described here may be used to diagnose Raynaud's phenomenon and to disclose an abnormal digital arterial response to cold before subjective symptoms have appeared. The test is approved by the health insurance authorities in Denmark.

We thank all workers and employers who took part in the study. The investigation was supported by the Danish Research Council of Technology and the Jubilee Fund of Nordic Coinsurance Company.

Requests for reprints to: Niels Olsen, Department of Clinical Physiology, Hvidovre Hospital, DK-2650 Hvidovre, Denmark.

\section{References}

1 Taylor W, Pelmear PL. Raynaud's phenomenon of occupational origin. An epidemiological survey. Acta Chir Scand 1976;suppl 465:27-32.

2 Nielsen SL, Lassen NA. Measurement of digital blood pressure after local cooling. J Appl Physiol 1977;43:907-10.

3 Taylor W, Pelmear PL. Vibration white finger in industry. London: Academic Press, 1975:xvii-xxii.

${ }^{4}$ Chatterjee DS, Petri A, Taylor W. Prevalence of vibrationinduced white finger in fluorspar mines in Weardale. $\mathrm{Br}$ $J$ Ind Med 1978;35:208-18.

${ }^{5}$ Olsen N, Nielsen SL. Prevalence of primary Raynaud phenomena in young females. Scand J Clin Lab Invest $1978 ; 37: 761-4$

- Raynaud M. De L'asphyxie locale et de la gangrene symmetrique des extremité. Paris: Leclerc, 1862:47-8.

${ }^{7}$ Hirai M, Nielsen SL, Lassen NA. Blood pressure measurements of all five fingers by strain gauge plethysmography. Scand J Clin Lab Invest 1976;36:627-32.

8 Olsen N, Nielsen SL. Diagnosis of Raynaud's phenomenon in quarrymen's traumatic vasospastic disease. Scand $J$ Work Environ Health 1979;5 :249-56.

${ }^{9}$ Nielsen SL. Raynaud phenomena and finger systolic pressure during cooling. Scand J Clin Lab Invest 1978;38: 765-70.

${ }^{10}$ Lewis T. Experiments relating to the peripherial mechanism involved in spasmodic arrest of the circulation in the fingers, a variety of Raynaud's disease. Heart 1929-31;15: 7-101.

${ }^{11}$ International Standardisation Organisation. Principles for the measurement and the evaluation of human exposure to vibration transmitted to the hand. Draft International Standard ISO/DIS 5349. Geneva: ISO, 1979.

12 Hellstrøm B, Andersen KL. Vibration injuries in Norwegain forest workers. Br J Ind Med 1972;29:255-63.

13 Pyykkö I. The prevalence and symptoms of traumatic vasospastic disease among lumberjacks in Finland. A field study. Work Environ Health 1974;11:118-31.

14 Färkkilä M, Pyykkö I, Korhonen O, Starck J. Hand grip forces during chain saw operation and vibration white finger in lumberjacks. Br J Ind Med 1979;36:336-41.

${ }^{15}$ Okada A, Yamashita T, Nagono C, Ikeda T, Yachi A, Shibata S. Studies on the diagnosis and pathogenesis of Raynaud's phenomenon of occupational origin. Br J Ind Med $1971 ; 28: 353-7$.

${ }^{16}$ Hirai M. Arterial insufficiency of the hand evaluated by digital blood pressure and arteriographic findings. Circulation 1978;58:902-8.

${ }^{17}$ James PB, Galloway RW. Arteriography of the hand in men exposed to vibration. In: Taylor $\mathrm{W}$, Pelmear PL, eds. Vibration white finger in industry. London: Academic Press, 1975:31-42.

${ }^{18}$ Ashe WF, Williams N. Occupational Raynaud's II. Arch Environ Health 1964;9:425-33.

19 Pelmear PL, Taylor W, Pearson JCG. Clinical objective tests for vibration white finger. In: Taylor W, Pelmear PL, eds. Vibration white finger in industry. London: Academic Press, 1975:53-81. 